\title{
Haemorrhagic thiamine deficient encephalopathy following prolonged parenteral nutrition
}

\author{
A O Vortmeyer, C Hagel, R Laas
}

\begin{abstract}
Neuropathological examination of three patients who were maintained on parenteral nutrition without substitution of thiamine demonstrated an acute haemorrhagic encephalopathy. The lesions differed substantially from the classic features of thiamine deficient encephalopathy regarding the histopathological alterations and the topographical distribution. The extreme rapidity of thiamine deprivation may have been responsible for the abrupt clinical onset of the disease and the intensity of the morphological alterations.
\end{abstract}

(F Neurol Neurosurg Psychiatry 1992;55:826-829)

Thiamine deficiency causes a wide spectrum of morphological alterations in the CNS. The classic features of thiamine deficient encephalopathy can be characterised by degeneration of myelin, extravasation of macrophages, prominence of the capillaries and relatively lesser involvement of neurons. This pattern is usually observed in the mamillary bodies, and, in severe cases, also involves the hypothalamus and the lower brain stem. Many cases show neuronal necrosis in the thalamus, predominantly in its medial nucleus.

The clinical features of Wernicke's encephalopathy include ophthalmoparesis, nystagmus, ataxia, acute apathetic-confusional state and coma. ${ }^{1-3}$ Since "Wernicke's encephalopathy" has different clinical and morphological interpretations, we prefer the aetiological description "thiamine deficient encephalopathy". Among the few morphological reports about acute thiamine deficiency following prolonged parenteral nutrition ${ }^{45}$ one case with a purely haemorrhagic encephalopathy without mesenchymal tissue reactions was reported. ${ }^{4}$

We present three patients with thiamine deficient encephalopathy who died in coma after prolonged parenteral nutrition without substitution of thiamine.

\section{Case reports}

Case 1 A 62 year old male alcoholic was admitted to hospital with a four days history of severe headache radiating down to his neck and visual disturbances. The patient was disoriented and showed a left abducens nerve palsy. Cerebral angiography revealed an aneurysm of the the anterior communicating artery which was clipped three days later without complications.

During the first days after surgery the patient regained consciousness and the neurological signs subsided. He developed left ventricular failure, pneumonia, and severe metabolic acidosis. Twenty one days after surgery consciousness gradually decreased. The patient became comatose, septicaemic and died on the 25th day after the operation. During the hospital stay he was fed intravenously with amino acids and $40 \%$ glucose.

Necropsy revealed severe pulmonary oedema and left ventricular hypertrophy (heart weight $560 \mathrm{~g}$ ) with high grade coronary and less pronounced general arteriosclerosis.

Case 2 A 71 year old woman was admitted because of painless jaundice and general weakness. There was no history of chronic alcoholism. Bilirubin and liver enzymes were elevated. Needle biopsy revealed a well differentiated tubular adenocarcinoma of the common bile duct. There was no evidence of haematogenous or lymphogenic spread. A central bile duct resection and a hemihepatectomy of the left lobe with cholangio-duodenostomy were performed. Postoperatively oral food led to persistent vomiting and the patient had to be fed parenterally. She recovered well until the ninth day when her general condition deteriorated.

Body temperature increased suddenly on the 20th day and an antibiotic regime was started. The patient developed progressive renal and hepatic failure and pulmonary infiltration which did not respond to antibiotic therapy. She died on the 24th day after the operation. She had been on continuous parenteral nutrition from the day of operation until death and had never been substituted with thiamine.

Necropsy findings showed a subphrenic abscess and a loosened texture of the spleen, small subendocardial and renal haemorrhages (suggesting septic shock) and a terminal acute pancreatitis. No residual tumour tissue was found in the liver and bile duct structures and no lymphogenic or hematogenous metastasis was present.

Case 3 A 38 year old female patient was given 6-thioguanin, cytosine-arabinoside and daunorubicin for acute myeloid leukaemia which caused frequent vomiting. Fourteen days after therapy the bone marrow showed persisting myeloblasts and the chemotherapy was repeated. The bone marrow then became aplastic with persisting nests of leukaemic blast cells. The patient developed fever and severe 

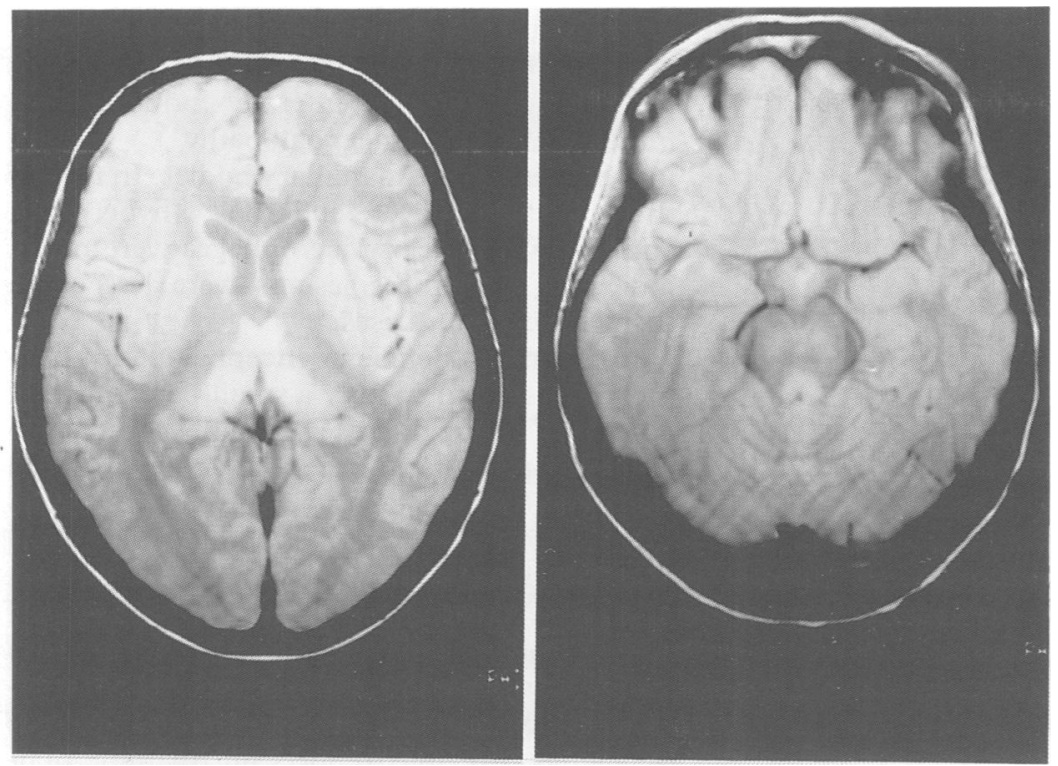

Figure 1 MRI (case 3) which was performed two days before death and shows increased signal intensity in the medial thalami (left) and the floor of the fourth ventricle (right). No bleedings can be observed. Obviously the haemorrhages occurred at a very late stage of the disease which was corroborated by the histopathological picture.
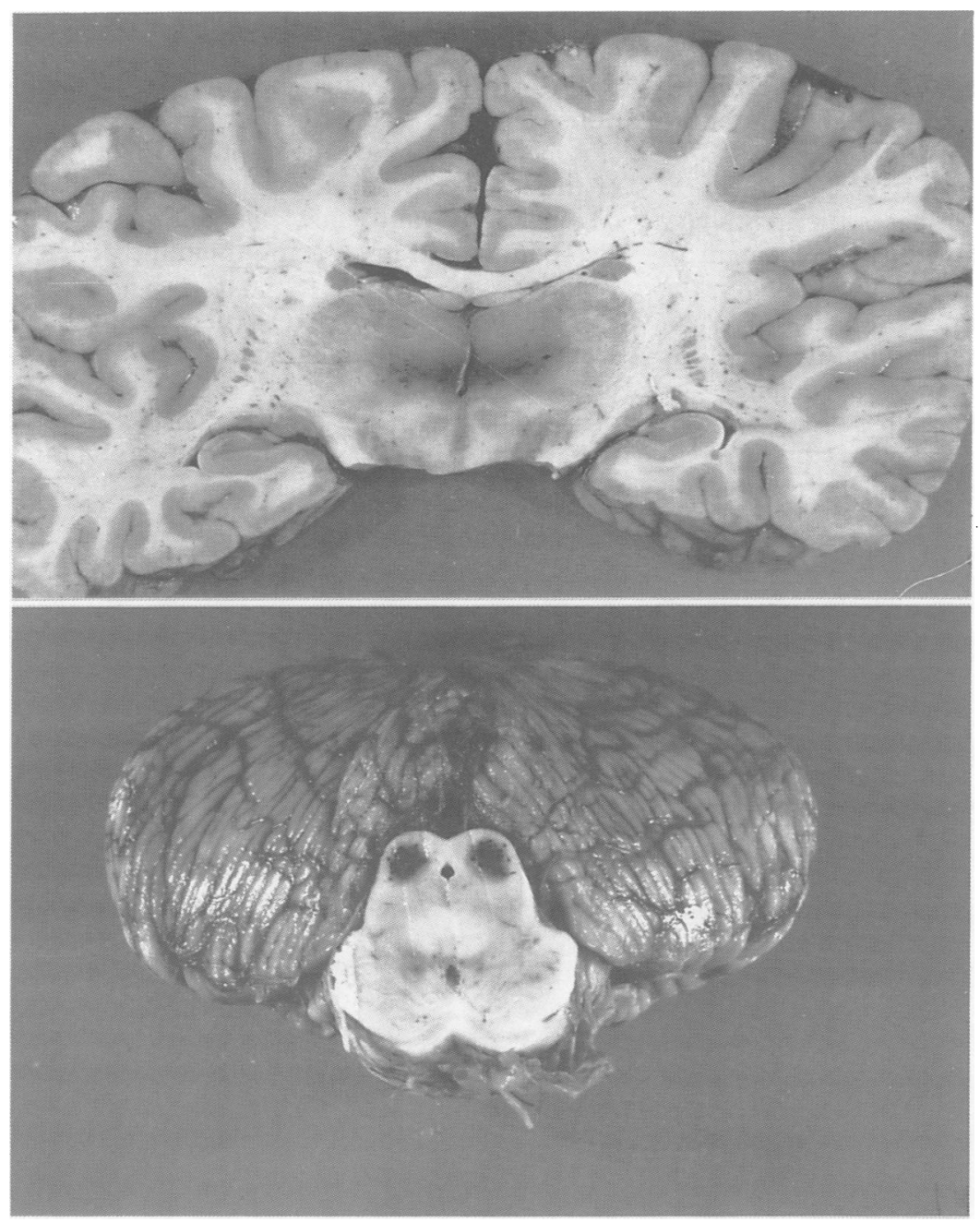

Figure 2 Haemorrhagic encephalopathy in basal thalamic areas (top) and the inferior colliculi (bottom). the ICU because of respiratory failure. CSF and CCT were normal but MRI revealed increased signal intensity in the medial nuclei of the thalamus on both sides (fig 1). The patient became comatose and died 11 days after the onset of fever. For the previous 26 days she had been maintained on parenteral dextrose and electrolyte solutions.

Necropsy revealed severe stomatitis, oesophagitis, proctitis and necrotising pneumonia with septic intravascular thrombi due to candida albicans. Bone marrow was aplastic and sierotic with nests of persisting myeloblasts. The spleen was also siderotic. Numerous haemorrhages in the skin and mucous membranes were found.

NEUROPATHOLOGICAL FINDINGS

All cases showed a symmetrical distribution of multiple small fresh haemorrhages in the inferior colliculi (fig 2). Cases 1 and 3 additionally exhibited extensive haemorrhages in the thalamus (fig 2), the hypothalamus and the floor of the fourth ventricle (fig 3). The mamillary bodies showed minimal affection with small petechial haemorrhages in a circumscribed area in case 3, in cases 1 and 2 the mamillary bodies were not affected, neither by haemorrhages nor by tissue spongiosis. Capillary proliferation and extravasation of macrophages were missing in all cases.

In all three cases the medial parts of the medial thalamic nuclei demonstrated acute eosinophlic nerve cell necroses (fig 4, lower left) extending over the whole medial nucleus in one case. The affected areas in the brainstem showed some spongiosis between the haemorrhages without interstitial infiltration of macrophages. The nerve and glial cells were morphologically intact. In case 3 additionally bilateral symmetrical softening and haemorrhage was observed in the superior vermis (fig 3).

In general, capillaries were unaltered within the affected regions (fig 4, upper left). In cases 1 and 2, few mitotic figures within endothelial cells in the inferior colliculi indicating an early stage of proliferative activity could be observed.

\section{Discussion}

Experimental and clinical observations established the aetiology of thiamine deficient encephalopathy in the late thirties experimentally ${ }^{6}$ and clinically. ${ }^{7}$ Patients maintained on prolonged parenteral nutrition without substitution of thiamine represent a special risk group for the development of a very severe course of this disease since the depletion of body thiamine stores occurs with a high rapidity. ${ }^{8}$ Moreover, the parenteral carbohydrate load in these patients requires full catalytic activity of thiamine for the prevention of tissue acidosis due to accumulation of pyruvate and lactate. Although the histopathological alterations of our cases show marked differences compared with the classic tissue syndrome of thiamine deficient encephalopathy, there is striking evidence that they demonstrate an especially 


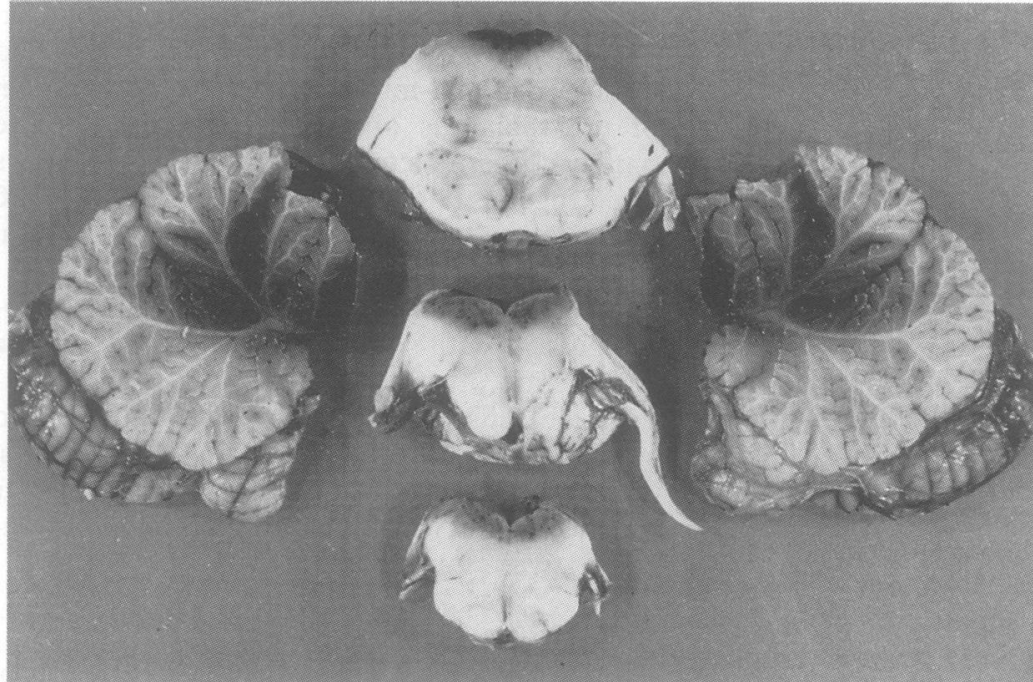

Figure 3 Haemorrhagic encephalopathy with involvement of the lower brain stem and the superior vermis cerebelli.

acute form of this tissue syndrome: first, there is an exact symmetry of the lesions in all affected areas including the thalamus which was described by Wernicke himself in $1881,{ }^{10}$ and no case with unilateral or asymmetric involvement of any predilection site has been reported so far in thiamine deficient encephalopathy.

Furthermore, in all cases typical predilection sites are involved. In two cases the mamillary bodies were spared. However, involvement of the mamillary bodies is not essential for the diagnosis of thiamine deficient encephalopathy. ${ }^{11}$ It is interesting that in some cases of hyperacute thiamine deficiency the mamillary bodies may be spared as in our cases 1 and 2, because intact mamillary bodies with typical lesions in other predilection sites on

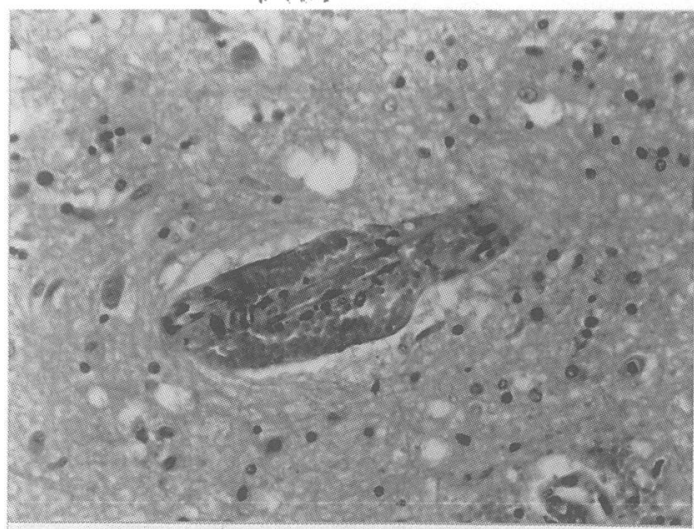

MRI do not exclude the diagnosis of thiamine deficient encephalopathy. All five previously reported cases of parenterally induced thiamine deficient encephalopathy ${ }^{45}$ showed involvement of the mamillary bodies. In four of these cases, however, endothelial hyperplasia and extravasation of macrophages were noted indicating that these lesions were less acute than those of our cases.

In thiamine deficient encephalopathy haemorrhages occur in only a small percentage of cases. $^{12-14}$ These figures are mainly confined to alcoholic patients. Studies on acute thiamine deficient encephalopathy in exclusively nonalcoholic patients with thiamine depletion from protracted vomiting were carried out in the 1930 s and 1940 s on 28 patients. ${ }^{15-17}$ All of them exhibited haemorrhagic lesions. Thus haemorrhages appear to be a very characteristic feature of intense forms of thiamine deficiency. Previous reports on thiamine deficient encephalopathy following prolonged intravenous therapy regularly described haemorrhagic lesions. ${ }^{45}$ One purely haemorrhagic case without cellular reaction or endothelial hyperplasia was reported ${ }^{4}$ which agrees with our findings.

The well demarcated haemorrhagic alterations restricted to the superior vermis in case 3 closely resemble the topographical distribution of the lesions in chronic "alcoholic cerebellar degeneration" and show that this region may also be involved in an acute thiamine deficient situation.

In thiamine deficient encephalopathy bilaterally symmetrical thalamic nerve cell necrosis occurs in a high percentage of cases, ${ }^{1819}$ predominantly in the medial nuclei. An acute type of these lesions was observed in our three cases. The thalami appeared to be the only
Figure 4 Typical perivascular haemorrhages around unaltered capillaries in case 3 (upper left, $\times 235$ ) and in the thiamine deficient rat (upper right, $\times 470$ ). Eosinophilic nerve cell necrosis in the thalamus of case 1 (lower left, $\times 235$ ) and within the thalamus of a thiamine deficient rat (lower right, $\times 235$ ).

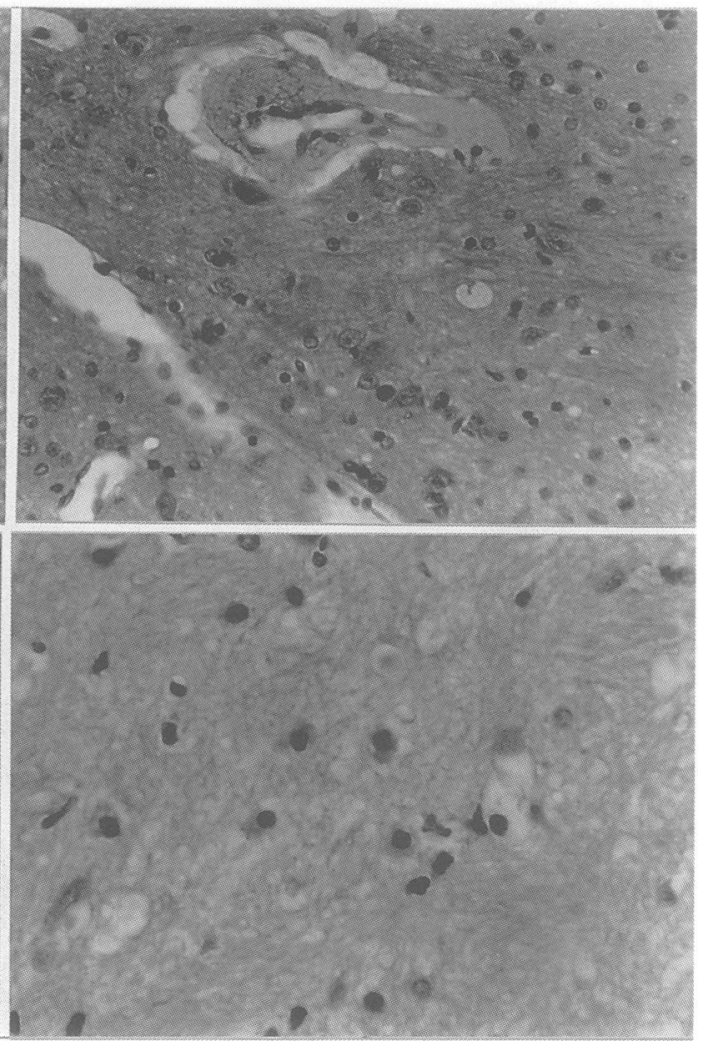


areas with irreversible nerve cell necrosis. This agrees with the clinical observation that acute recovery from brain stem symptoms is often followed by a chronic Korsakoff amnesic state. ${ }^{17}$

The brain lesions in our cases are nearly identical to the tissue alterations in the experimental model of pyrithiamine induced acute thiamine deficient encephalopathy of the rat. $^{2021}$ This model combines dietary deprivation in rats with administration of pyrithiamin, a thiamine antagonist, and leads to a more rapid course of the disease compared with exclusive dietary deprivation. The experimental lesions are characterised by multiple bleedings from unaltered vessels in the brain stem and the thalamus (fig 4, upper right) with predilection sites in the inferior colliculi. As in humans, eosinophilic nerve cell necrosis is consistently observed in basal thalamic regions (fig 4, lower right). Furthermore, the mamillary bodies may be spared. ${ }^{21}$ Because of the obvious similarities between the morphological alterations in the human cases and the experimental model we conclude that the extreme rapidity of thiamine deprivation in these patients may be responsible for the abrupt onset of clinical symptoms and the fresh haemorrhagic cerebral lesions.

We thank Mrs Selhorst for skillful laboratory work, and Dr Neumaier Probst and Professor Zanella for interpreting the MRIs.

1 Victor M, Adams RD, Collins GH. The Wernicke-Korsakoff syndrome and related neurologic disorders due to alcoholism syndrome and related neurologic disorders due to alcoho

2 Koeppen AH, Daniels JC, Barron KD, Hines I. Subnormal body temperatures in Wernicke's Encephalopathy. Arch Neurol 1969;21:493-8.
3 Ackerman WJ. Stupor, bradycardia, hypotension and hypothermia: A clinical presentation of Wernicke's encephalopathy with rapid response to thiamine. West $\mathcal{f}$ Med phalopathy with

4 Nadel AM, Burger PC. Wernicke's encephalopathy following prolonged intravenous therapy. $\mathscr{f A M A} 1976$ 235:2403-5

5 Harper CG. Sudden, unexpected death and Wernicke's encephalopathy: A complication of prolonged intravenous feeding. Aust NZ $\mathcal{F}$ Med 1980;10:230-5.

6 Alexander L. Wernicke's disease. Identify of lesions produced experimentally by $\mathrm{B} 1$ avitaminosis in pigeons with hemorrhagic polioencephalitis occurring in chronic alcoholism in man. Am $\mathcal{F}$ Pathol 1940;16:61-9.

7 Jolliffe N, Wortis H, Fein HD. The Wernicke Syndrome. Arch Neurol Psychiat 1941;46:569-97.

8 Blennow G. Wernicke's encephalopathy following prolonged artificial nutrition. Amer f Dis Child 1975;129:1456.

9 Witt ED. Neuroanatomical consequences of thiamine deficiency: A comparative analysis. Alcohol Alcohol 1985; 20:201-21.

10 Wernicke C. Die acute, hämorrhagische Polioencephalitis superior. Lehrbuch der Gehirnkrankheiten für Arzte und Studirende. Band II, Dritter Theil, S47 S229-42. Kassel: Fischer, 1881.

11 Riggs HE, Boles RS. Wernicke's disease. A Clinical and Pathological study of 42 cases. Qf Stud Alcohol 1944 5:361-70.

12 Gamper E. Zur Frage der Polioencephalitis haemorrhagica der chronischen Alkoholiker. Anatomische Befunde beim alkoholischen Korsakow und ihre Beziehungen zum klinichsen Bild. Dtsch Z Nervenh 1928;102:119-29.

13 Rosenblum WI, Feigin I. The Hemorrhagic Component of Wernicke's Encephalopathy. Arch Neurol 1965;13: 627-37.

14 Grunnet ML. Changing incidence, distribution, and histopathology of Wernicke's polioencephalopathy. Neurology 1969;19:1135-9.

15 Neubürger $K$. Über die nichtalkoholische Wernickesche Krankheit, insbesondere über ihr Vorkommen beim Krebsleiden. Virchows Arch Pathol Anat 1937;298:68-86.

6 Campbell ACP, Biggart JH. Wernicke's encephalopath (Polioencephalitis haemorrhagica superior): Its alcoholic and non-alcohoic incidence. F Pathol Bacteriol 1939; 48:245-62.

17 Barrie HJ. Wernicke's encephalopathy in surgical practice. Report of three cases. Lancet 1947;2:278-9.

18 Colmant HJ. Enzephalopathien bei chronischem Alkoholabusus. Stuttgart: Ferdinand Enke Verlag, 1965.

19 Torvik A. Two Types of Brain Lesions in Wernicke's Encephalopathy. Neuropath Appl Neurobiol 1985;11: Enceph $179-90$.

20 Troncoso JC, Johnston MV, Hess KM, Griffin JW, Price DL. Model of Wernick's Encephalopathy. Arch Neurol 1981;38:350-4.

21 Vortmeyer AO, Colmant HJ. Differentiation between brain lesions in experimental thiamine deficiency. Virchows Archiv A Pathol Anat 1988;414:61-7. 